\title{
Parallel evolution of facial stripe patterns in the Neolamprologus brichardi/pulcher species complex endemic to Lake Tanganyika
}

\author{
Nina Duftner ${ }^{\text {a,b,c }}$, Kristina M. Sefc ${ }^{\text {a }}$, Stephan Koblmüller ${ }^{\text {a }}$, Walter Salzburger ${ }^{\text {d,f }}$, \\ Michael Taborsky ${ }^{\mathrm{e}}$, Christian Sturmbauer ${ }^{\mathrm{a}, *}$ \\ ${ }^{a}$ Department of Zoology, University of Graz, Universitätsplatz 2, A-8010 Graz, Austria \\ ${ }^{\mathrm{b}}$ FAS Center for Systems Biology, Harvard University, 7 Divinity Avenue, Cambridge, MA 02138, USA \\ ${ }^{\mathrm{c}}$ Section of Integrative Biology, University of Texas at Austin, 1 University Station \#C0930, Austin, TX 78712, USA \\ ${ }^{\mathrm{d}}$ Department of Ecology and Evolution (DEE), University of Lausanne, UNIL Sorge, Le Biophore, CH-1015 Lausanne, Switzerland

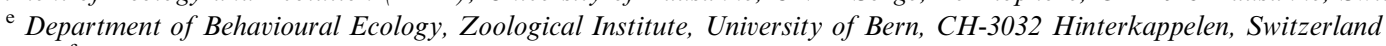 \\ ${ }^{\mathrm{f}}$ Zoological InstitutelEvolutionary Biology, University of Basel, Vesalgasse 1, CH-4051 Basel, Switzerland
}

Received 6 March 2007; revised 2 August 2007; accepted 7 August 2007

Available online 15 August 2007

\begin{abstract}
Colour pattern diversity can be due to random processes or to natural or sexual selection. Consequently, similarities in colour patterns are not always correlated with common ancestry, but may result from convergent evolution under shared selection pressures or drift. Neolamprologus brichardi and Neolamprologus pulcher have been described as two distinct species based on differences in the arrangement of two dark bars on the operculum. Our study uses DNA sequences of the mitochondrial control region to show that relatedness of haplotypes disagrees with species assignment based on head colour pattern. This suggests repeated parallel evolution of particular stripe patterns. The complete lack of shared haplotypes between populations of the same or different phenotypes reflects strong philopatric behaviour, possibly induced by the cooperative breeding mode in which offspring remain in their natal territory and serve as helpers until they disperse to nearby territories or take over a breeding position. Concordant phylogeographic patterns between $N$. brichardi/N. pulcher populations and other rock-dwelling cichlids suggest that the same colonization routes have been taken by sympatric species and that these routes were affected by lake level fluctuations in the past.
\end{abstract}

(C) 2007 Elsevier Inc. All rights reserved.

Keywords: Cichlids; Stripe patterns; Lake level fluctuations; Evolution; mtDNA; Cooperative breeding

\section{Introduction}

Colour pattern diversity within or between populations is often not merely due to random genetic variation but rather generated and maintained by selection. Consequently, colour pattern similarities are not always correlated with common ancestry, but may result from convergent evolution under shared selection pressures (Meyer, 2006). For example, adaptive camouflage to minimize predation risk evolved repeatedly in beach mice (Hoekstra et al., 2006), and the convergent evolution of

\footnotetext{
* Corresponding author. Fax: +43316 3809875.

E-mail address: christian.sturmbauer@uni-graz.at (C. Sturmbauer).
}

cryptic colour patterns in anurans inhabiting similar habitats has been attributed to selection by visual predators (Hoffman and Blouin, 2000; Thorpe and Stenson, 2003). Convergent aposematic colouration, signalling inedibility to potential predators, may represent Müllerian mimicry (Brower, 2006; Chiari et al., 2004; Jiggins et al., 2006; Joron et al., 2006; Sanders et al., 2006). Parallel evolution of colour patterns can also be driven by sexual selection in an ecological context (Boughman et al., 2005), such as when recurrent habitat differences or receiver biases favour alternative nuptial colours (Allender et al., 2003). The genetic mechanisms underlying colour pattern convergence are not well understood. In some cases, genetic modifications of homologous genes result in the same phenotype 
of distantly related species, whereas in other instances different genetic mechanisms may lead to the same pattern elements (Brower, 2006; Hoekstra et al., 2006; Joron et al., 2006; Prud'homme et al., 2006).

Different facial stripe patterns and associated blue and/ or yellow colour markings on the head distinguish the two endemic cichlid species Neolamprologus brichardi and Neolamprologus pulcher, both rock-dwelling members of the tribe Lamprologini in Lake Tanganyika. Neolamprologus brichardi and $N$. pulcher are cooperative breeders where 1-14 offspring of both sexes continue to stay as helpers in the territory of the dominant breeding pair to take part in territory defence and brood care (Balshine et al., 2001; Taborsky, 1984, 1994; Taborsky and Limberger, 1981). The two taxa were originally described as subspecies of Neolamprologus savoryi (Trewavas and Poll, 1952) but were later elevated to species status (Poll, 1974). The main difference between $N$. brichardi and $N$. pulcher lies in their operculum markings: two black bars arranged in the shape of a horizontal ' $\mathrm{T}$ ' in $N$. brichardi and arranged as two vertical curved bars in N. pulcher (Fig. 1). The distribution of the two species along the lake shore is discontinuous, with $N$. brichardi in the northern half of the lake as well as in several stretches of coastline in the south, and $N$. pulcher exclusively in the south (Fig. 1; Konings, 1998). They are never found sympatrically, but may occur in close vicinity to each other, e.g. on either side of a habitat barrier such as a river estuary. At one location in the south (Chaitika), the phenotype of the resident population has been described as intermediate between $N$. brichardi and N. pulcher (Konings, 1998).

One purpose of the present study was to determine whether the operculum markings used for species distinction are useful systematic characters, or whether parallel evolution repeatedly created the two alternative phenotypes. If the current classification of $N$. brichardi and $N$. pulcher as two distinct species is correct, we expect the populations to segregate according to phenotype in a phylogenetic reconstruction, provided that the divergence time is sufficiently long for lineage sorting to be completed. If the alternative phenotypes do not represent phylogenetic clusters, multiple events of convergent evolution of the supposedly diagnostic traits render the taxonomic status of the two taxa uncertain. The second aim of this study was to unravel the phylogeographic pattern of populations of both taxa. Recent studies showed that the extant phylogeography and population structure of many of the over 200 endemic cichlid species in Lake Tanganyika was shaped by two main factors, lake level fluctuations and habitat barriers, and that major phylogeographic patterns agree across ecologically diverse species (Baric et al., 2003; Duftner et al., 2006; Koblmüller et al., 2007; Rüber et al., 2001; Sefc et al., 2007; Sturmbauer et al., 2001, 2005; Taylor et al., 2001). Notably, the majority of these studies has focussed exclusively on mouthbrooders that are characterized by a markedly different reproductive ecology compared to the substrate-brooding Lamprologini. In contrast to the large species flocks of Lakes Malawi and Victoria, which exclu- sively comprise mouthbrooding cichlids, substrate-spawners make up almost half the number of cichlid species in Lake Tanganyika. Here, we compare the genetic structure within and between populations of the two Neolamprologus taxa with that of other rock-dwelling cichlids in order to unravel phylogeographic similarities shared by species that display the same or a different breeding strategy and live in the same habitat.

\section{Materials and methods}

\subsection{Sampling and DNA extraction}

A total of 81 individuals of $N$. brichardi and $N$. pulcher were included in our study (Table 1), comprising three previously published sequences that were downloaded from GenBank (AF400721, AF438785, AF438787). Samples were collected during field expeditions to Lake Tanganyika in 2000, 2001 and 2002. Variabilichromis moorii, which occupies an ancestral branch within the lamprologine phylogeny (Colombe and Allgayer, 1985; Poll, 1986; Sturmbauer et al., 1994), was used as outgroup taxon (AF438776). Tissue samples were preserved in 96\% ethanol and stored at room temperature until further processing. Genomic DNA was extracted by applying proteinase $K$ digestion followed by ethanol precipitation.

\subsection{Amplification and sequencing of the mitochondrial DNA control region}

Partial sequences of the mitochondrial DNA control region were amplified with the primers THR-2 (Kocher et al., 1989) and TDK-D (Lee et al., 1995). The total reaction volume of $17 \mu 1$ contained $0.085 \mu 1$ of Taq DNA polymerase (BioTherm ${ }^{\mathrm{TM}}$ ), $1.7 \mu \mathrm{l}$ of each primer $(10 \mu \mathrm{M}), 1.7 \mu \mathrm{l}$ $10 \times$ dNTP solution, $1.7 \mu \mathrm{l} 10 \times \mathrm{MgCL}_{2}$ buffer, $1.62 \mu \mathrm{l}$ enzyme diluent (Idaho Technology), $6.8 \mu \mathrm{l}$ water, and $1.7 \mu 1$ genomic DNA. PCR-amplification was performed on an Air-Thermo Cycler (Idaho Technology) under the following conditions: an initial denaturation at $94{ }^{\circ} \mathrm{C}$ for $15 \mathrm{~s}$ was followed by 40 cycles with denaturation at $94{ }^{\circ} \mathrm{C}$ for $0 \mathrm{~s}$, primer annealing at $52{ }^{\circ} \mathrm{C}$ for $0 \mathrm{~s}$, and extension at $72{ }^{\circ} \mathrm{C}$ for $15 \mathrm{~s}$. The PCR-products were purified in an enzymatic reaction with ExoSAP-IT (Exonuclease I and Shrimp Alkaline Phosphatase in buffer). Chain termination sequencing followed the protocol of Koblmüller et al. (2004) by using the forward primer THR-2 (Kocher et al., 1989). DNA fragments were purified by applying a standard ethanol precipitation and subsequently analyzed with an ABI 373 Automatic DNA Sequencer (Applied Biosystems). Sequences were deposited in GenBank under the Accession Nos. EF137273-EF137353.

\subsection{Phylogenetic and phylogeographic analysis}

Sequencing yielded 55 haplotypes that were individually screened in Sequence Navigator (Applied Biosystems), and 


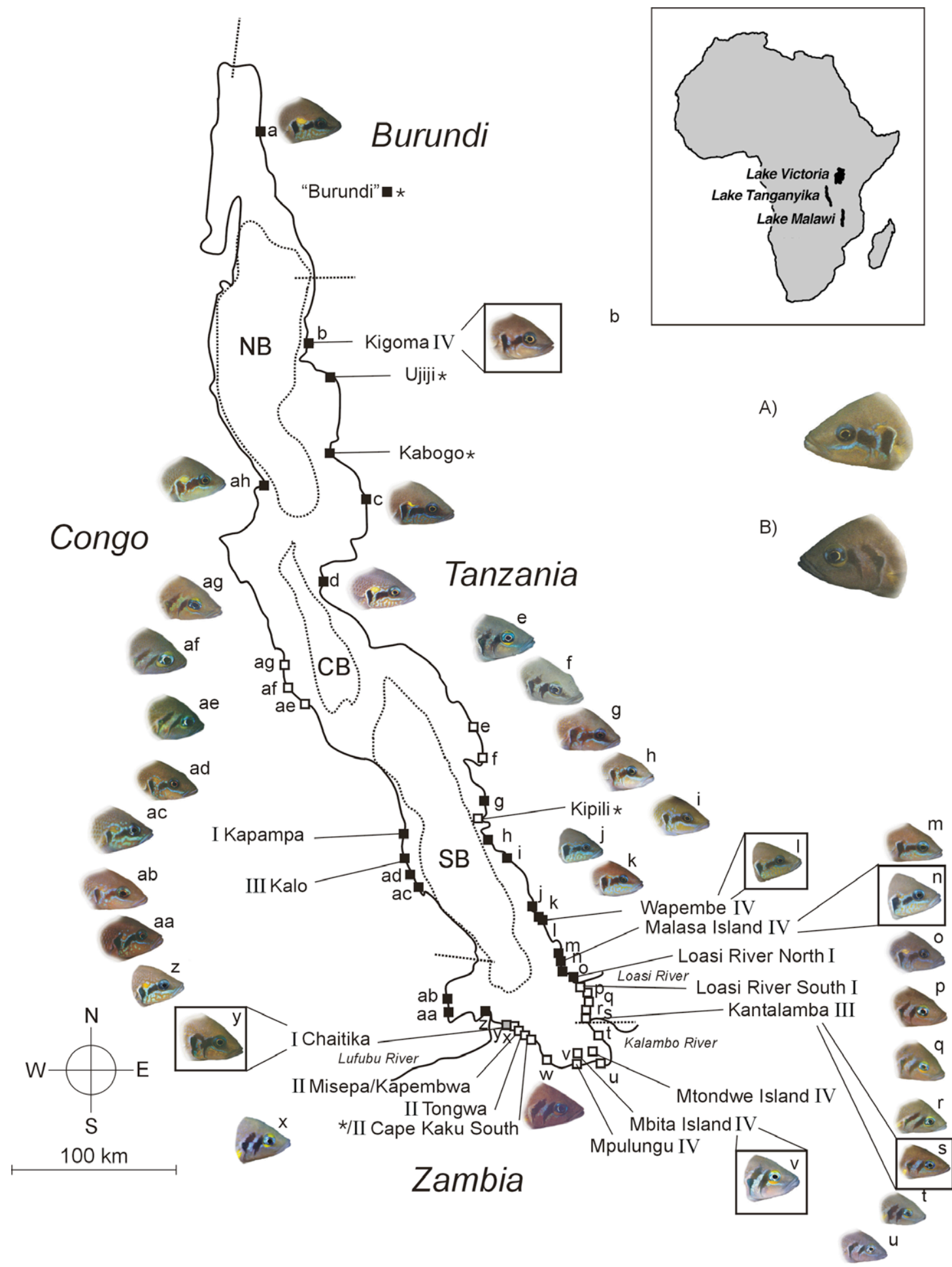

Fig. 1. Map of Lake Tanganyika with sampling sites and facial stripe patterns of Neolamprologus brichardi and N. pulcher. Squares along the lake shore with lower case letters and corresponding pictures of phenotypes refer to populations that have been photographed by Ad Konings (1998). Differences in hue are mainly due to variations in light conditions and light exposure. For this study, only the orientation of facial stripe patterns is crucial. Sampling sites are indicated by locality name and either roman number of clade to which the mtDNA haplotypes of the population were assigned, or an asterisk for haplotypes that could not be assigned to any cluster in the TCS-network analysis (Fig. 2). When there is an overlap between our and Konings' sampling sites, pictures of phenotypes are framed. Full squares indicate the occurrence of $N$. brichardi-, open squares of $N$. pulcher-, and shaded squares of intermediate phenotypes. (A) N. brichardi at Loasi River North, (B) N. pulcher at Loasi River South (photographs provided by H. Büscher) as examples of two very distinct phenotypes in close geographic proximity that have been included in our study.

subsequently aligned in SE-AL (Rambaut, 1996). The final alignment comprised 82 sequences with a total length of
443 base pairs (bp). Phylogenetic trees based on neighbour joining (NJ) as well as Bayesian Inference (BI) were calcu- 
Table 1

Sampling localities, sample sizes, geographic coordinates and species assignment according to phenotype

\begin{tabular}{|c|c|c|c|c|}
\hline Locality & $\begin{array}{l}\text { Sample } \\
\text { size }\end{array}$ & Latitude & Longitude & Species assignment \\
\hline Burundi & 1 & $?$ & $?$ & N. brichardi \\
\hline Kabogo & 1 & $5^{\circ} 67^{\prime}$ & $29^{\circ} 77^{\prime}$ & N. brichardi \\
\hline Kalo & 1 & $7^{\circ} 45^{\prime}$ & $30^{\circ} 30^{\prime}$ & $N$. brichardi \\
\hline Kapampa & 2 & $7^{\circ} 30^{\prime}$ & $30^{\circ} 12^{\prime}$ & N. brichardi \\
\hline Kigoma & 3 & $4^{\circ} 88^{\prime}$ & $29^{\circ} 67^{\prime}$ & N. brichardi \\
\hline $\begin{array}{l}\text { Loasi River } \\
\text { North }\end{array}$ & 9 & $8^{\circ} 17^{\prime}$ & $31^{\circ} 00^{\prime}$ & N. brichardi \\
\hline Malasa Island & 5 & $8^{\circ} 12^{\prime}$ & $30^{\circ} 56^{\prime}$ & $N$. brichardi \\
\hline Ujiji & 1 & $4^{\circ} 54^{\prime}$ & $29^{\circ} 40^{\prime}$ & N. brichardi \\
\hline Wapembe & 1 & $8^{\circ} 00^{\prime}$ & $30^{\circ} 53^{\prime}$ & N. brichardi \\
\hline Chaitika & 9 & $8^{\circ} 34^{\prime}$ & $30^{\circ} 47^{\prime}$ & $\begin{array}{l}N \text {. brichardil } N \text {. } \\
\text { pulcher }\end{array}$ \\
\hline $\begin{array}{l}\text { Cape Kaku } \\
\text { South }\end{array}$ & 4 & $8^{\circ} 41^{\prime}$ & $30^{\circ} 54^{\prime}$ & N. pulcher \\
\hline Kantalamba & 1 & $8^{\circ} 33^{\prime}$ & $31^{\circ} 10^{\prime}$ & $\begin{array}{l}\text { N. pulcher } \\
\text { "Daffodil" }\end{array}$ \\
\hline Kipili & 1 & $7^{\circ} 43^{\prime}$ & $30^{\circ} 60^{\prime}$ & N. pulcher \\
\hline $\begin{array}{l}\text { Loasi River } \\
\text { South }\end{array}$ & 13 & $8^{\circ} 19^{\prime}$ & $31^{\circ} 02^{\prime}$ & N. pulcher \\
\hline Mbita Island & 1 & $8^{\circ} 46^{\prime}$ & $31^{\circ} 06^{\prime}$ & N. pulcher \\
\hline $\begin{array}{l}\text { Misepa/ } \\
\text { Kapembwa }\end{array}$ & 24 & $8^{\circ} 36^{\prime}$ & $30^{\circ} 49^{\prime}$ & N. pulcher \\
\hline Mpulungu & 2 & $8^{\circ} 46^{\prime}$ & $31^{\circ} 06^{\prime}$ & N. pulcher \\
\hline $\begin{array}{l}\text { Mtondwe } \\
\text { Island }\end{array}$ & 1 & $8^{\circ} 42^{\prime}$ & $31^{\circ} 07^{\prime}$ & N. pulcher \\
\hline Tongwa & 1 & $8^{\circ} 40^{\prime}$ & $30^{\circ} 53^{\prime}$ & N. pulcher \\
\hline
\end{tabular}

lated in PAUP* (Swofford, 2000) and MrBayes 3.1.2 (Huelsenbeck and Ronquist, 2001), respectively, with Variabilichromis moorii used as outgroup species. A hierarchical likelihood ratio test in Modeltest version 3.7 (Posada and Crandall, 1998) suggested the Hasegawa-Kishino-Yano model (Hasegawa et al., 1985) HKY + I + G as the best fitting substitution model for the mitochondrial control region data set (gamma shape distribution parameter, 0.4947 ; proportion of invariable sites, 0.4320 ; base frequencies, A, 0.3504; C, 0.2282; G, 0.1403; T, 0.2811). For BI, 10 Markov chains (chain temperature 0.2 ) were run for two million generations, where a tree was sampled every 100 th generation. The burn-in value was set to 200 trees, and the remaining 19,800 trees were used to calculate posterior probabilities for the resulting tree topology. Uncertainties of phylogeny estimates in NJ were assessed by bootstrap analysis (1000 pseudo-replications). Alternative tree topologies were tested against the Bayesian consensus tree by means of a Kishino-Hasegawa test (Hasegawa and Kishino, 1989; Kishino and Hasegawa, 1989) in PAUP*. For this test, topologies were constrained for monophyly of $N$. brichardi and $N$. pulcher phenotypes regardless of geographic origin, and various constraints were enforced for the phenotypically intermediate population from Chaitika (Konings, 1998). The likelihood scores of the resulting evolutionary hypotheses were statistically compared to the unconstrained Bayesian tree. All taxa were collapsed to the level of phenotype: (1) ((N. brichardi)( $N$. pulcher $)($ Chaiti- ka))); (2) $((N . \quad$ pulcher $)((N . \quad$ brichardi $)($ Chaitika $))) ; \quad(3)$ ((Chaitika) $((N$. bricharid $)(N$. pulcher $)))$; (4) ((N. pulcher and Chaitika)(N. brichardi)); (5) (N. bricharidi and Chaitika)(N. pulcher)). The facial stripe patterns of the two phenotypes $N$. brichardi and $N$. pulcher as well as the intermediate phenotype from Chaitika were mapped onto the Bayesian phylogeny in MacClade (Maddison and Maddison, 1992). The phylogeographic relationships among haplotypes were visualized by constructing a network based on statistical parsimony with the TCS software package (Clement et al., 2000), which is based on an approach developed by Templeton et al. (1992).

\section{Results}

\subsection{Multiple origins of the "brichardi" phenotype}

Phylogenetic analysis identified four main lineages, which correspond to the major clades identified from statistical parsimony (clades I-IV; see below) (Fig. 2). Statistical support for the main clusters ranged from 64 to 98 in NJbootstrapping, and amounted to 100 for Bayesian posterior probabilities. Within clades, the arrangement of taxa differed slightly depending on the algorithm employed and was not well supported. However, clearly, the phylogenetic reconstructions never reflected the current taxonomic separation of $N$. brichardi and $N$. pulcher, nor did they illustrate a genetic pattern tightly linked to current geographic distribution along the lakeshore. Haplotypes were not shared between populations. Three out of the four main clades comprised both phenotypes. Mapping the two different types of facial stripe patterns onto the Bayesian tree suggests that, within clade I, the "brichardi" phenotype evolved from "pulcher"-type ancestors three times. Clade II exclusively comprises "pulcher"-type populations from three locations within about $13 \mathrm{~km}$ of shoreline. Clade III groups one "pulcher"-type with one "brichardi"-type individual (haplotype divergence $1.6 \%$ ), without uncovering the putative ancestral facial pattern. In clade IV, the "brichardi" phenotype apparently evolved from "pulcher"-type ancestors three times, while the ancestral state of the remaining "brichardi"-type individuals could not be reconstructed. This may be due to geographically less dense taxon sampling compared to those instances where ancestral states were inferred.

Alternative tree topologies with reciprocal monophyly of $N$. brichardi and $N$. pulcher and different treatments of the intermediate Chaitika phenotype were rejected by the Kishino-Hasegawa test at the significance level $p<0.001$.

\subsection{Phylogeographic relationships between $m t D N A$ haplotypes}

The majority of mtDNA control region sequences (50 out of 55 haplotypes) of $N$. brichardi/N. pulcher populations were resolved as four independent networks in TCS, while five haplotypes could not be connected to 
any cluster (Fig. 2). Clade I comprised N. brichardi and $N$. pulcher samples from opposite locations at the south-

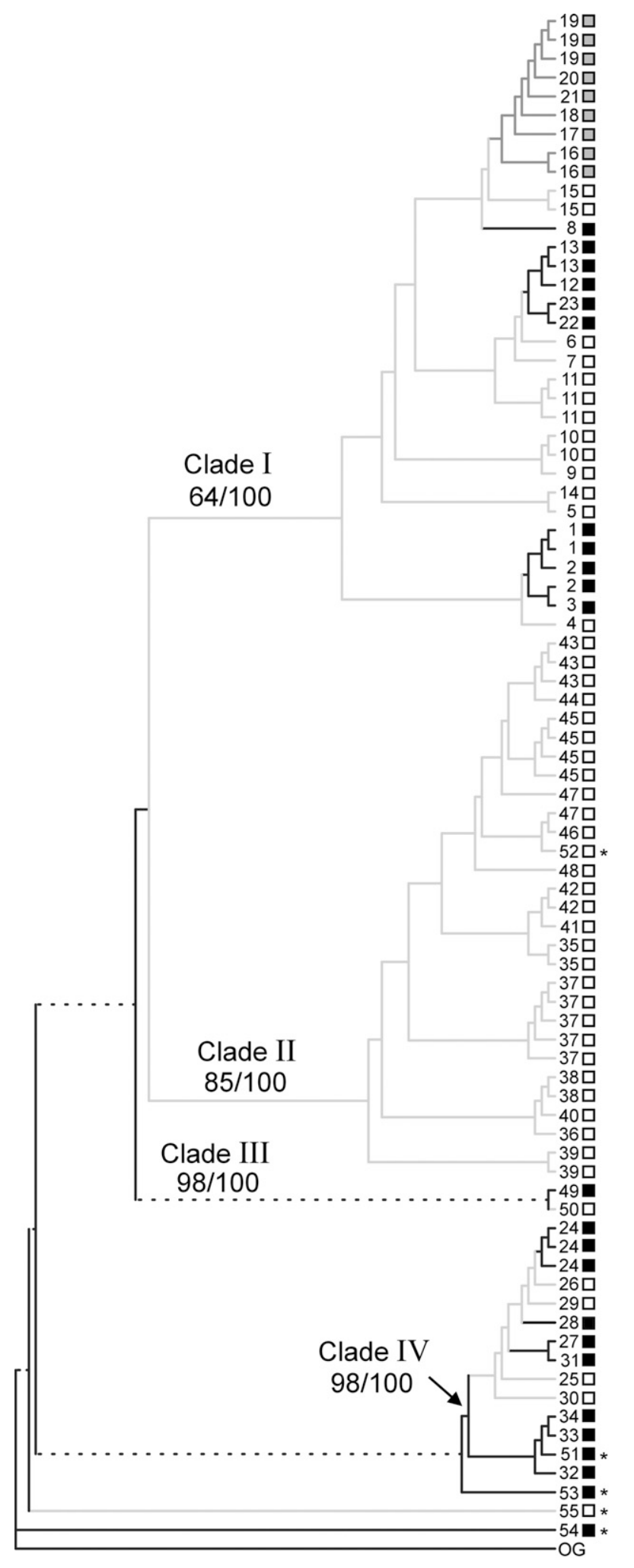

ern basin, Kapampa and Loasi River North ( $N$. brichar$d i)$, Loasi River South ( $N$. pulcher), as well as the
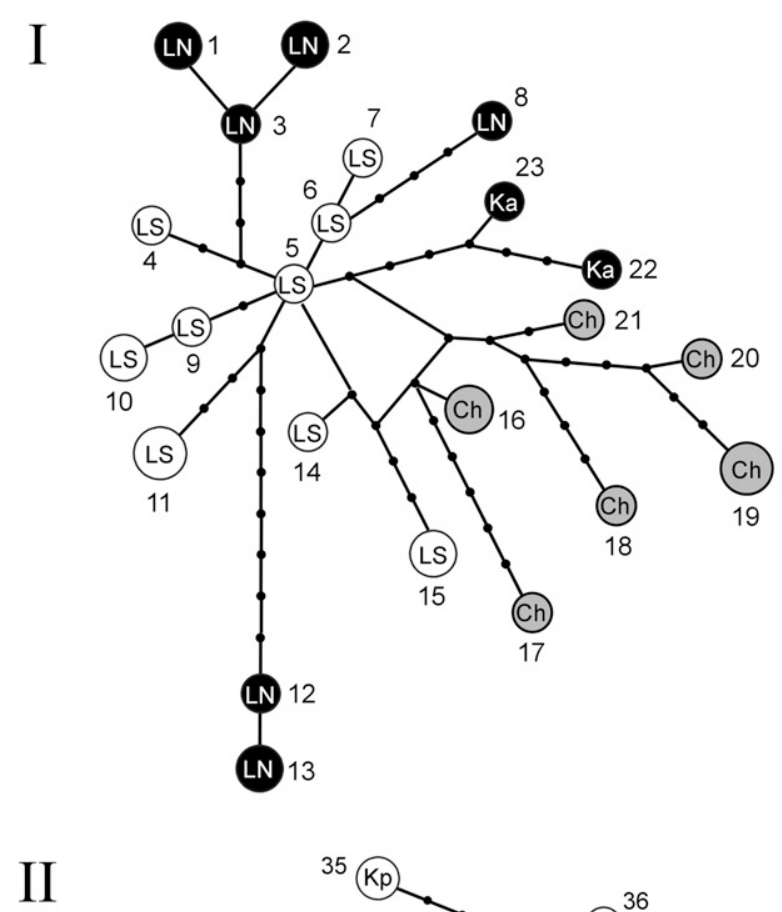

II

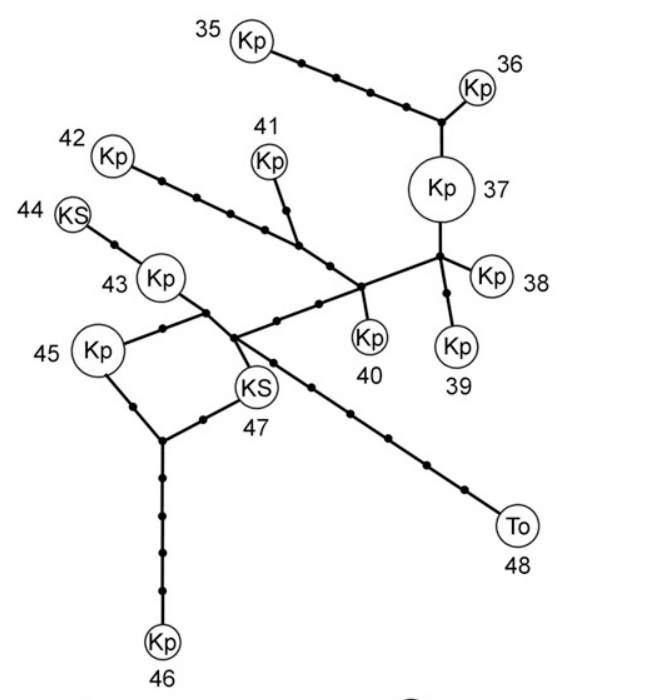

III

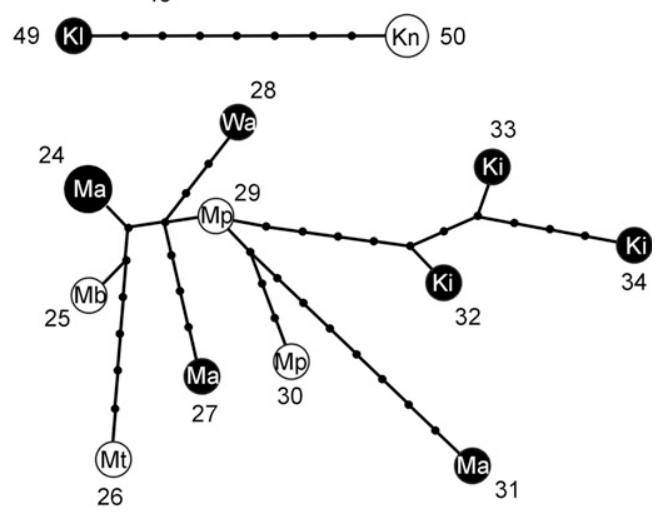

IV

Neolamprologus brichardi

Neolamprologus pulcher

N. brichardi/pulcher (intermediate phenotype)

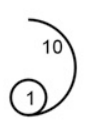


intermediate population from Chaitika. The second network, clade II, exclusively comprised haplotypes of $N$. pulcher from three nearby locations, Misepa/Kapembwa, Tongwa and Cape Kaku South. In the third network, two haplotypes from two remote locations were connected to each other by eight mutation steps: $N$. brichardi from Kalo (haplotype 29) and $N$. pulcher from Kantalamba (haplotype 50). The phenotype of the latter is also known as $N$. pulcher "Daffodil", which is characterised by $N$. pulcher-like facial stripe patterns and yellow unpaired fins, and occurs only at a very small section of the southern Tanzanian coast (Konings, 1998). Clade IV grouped $N$. pulcher and $N$. brichardi from distinct locations across the lake, and consisted of haplotypes from Malasa Island, Wapembe, and Kigoma ( $N$. brichardi) as well as from Mbita Island, Mtondwe Island, and Mpulungu ( $N$. pulcher). Each network contained long branches with only few reticulations and several missing haplotypes, maybe in part as a consequence of the moderate within-population sample sizes. It is remarkable that the mean sequence divergence in a clade of haplotypes from nearby locations (clade II, $1.5 \%$ ) is almost as high as that within clades that span almost the entire lakeshore (clade IV, 1.6\%; clade I, $1.9 \%$ ).

Five haplotypes remained unconnected to any of the networks. These comprise one haplotype from Cape Kaku South (haplotype 52) with an 11 base pair deletion, which was placed with other samples from the same region in the phylogeny; two samples from the northern part of the Lake, Kabogo (Tanzania; haplotype 53) and an unknown location in Burundi (haplotype 51), which were resolved in the clade comprising other northern samples in the phylogeny; and two further haplotypes, one from the northern basin (Ujiji; haplotype 54) and one from the southern basin (Kipili), which split at the base of the phylogenetic tree.

\section{Discussion}

\subsection{Parallel evolution of facial stripe patterns}

Our data do not support reciprocal monophyly of the Tanganyikan cichlids $N$. brichardi and $N$. pulcher. In contrast, the dark T-shaped gill-cover markings with associated blue and/or yellow patterns that identify $N$. brichardi evolved several times independently from pulcher-type ancestors. The intermediate phenotypes of $N$. pulcher at Chaitika (Konings, 1998) might represent a transitional state in stripe pattern evolution or, alternatively, are the result of previous hybridization events between the two phenotypes. However, given that our analysis is based on a single stretch of mtDNA our results need to be treated with some caution. As in birds (Hoekstra and Price, 2004) colour evolution is weakly constrained in East African cichlids (Seehausen et al., 1999), which seems particularly true for stripe patterns not associated with ecology such as orbital stripes, the lachrymal stripe and the preopercular stripe. While there is some evidence for hue to evolve under the force of sexual selection, hitherto no such associations have been found for the evolution of stripe patterns (Seehausen et al., 1999).

Within the Lake Tanganyika cichlid tribe Lamprologini, similar stripe patterns are sometimes found in species from different phylogenetic lineages (Salzburger et al., 2002). For instance, the two phylogenetically distinct species $N$. pulcher and Neolamprologus olivaceous share gill cover markings with two slightly curved vertical bars, and have even been regarded as one species based on morphological data (Snoeks, pers. comm.). Neolamprologus savoryi, Neolamprologus splendens and Neolamprologus helianthus all have facial stripes arranged in a V-shaped pattern.

Conspicuous stripes on the head might play a major role in the differentiation between species and the individual identification of conspecifics within populations (Seehausen et al., 1999). For cooperative breeders such as $N$. brichardi/ $N$. pulcher it is crucial to differentiate between familiar animals and strangers. When allowed to use visual cues only, members of $N$. brichardi breeding pairs identified their own helpers, and they could also distinguish unfamiliar helpers from non-helpers (Hert, 1985). Even when presented with video images, they individually identified conspecifics and fought strangers but courted mates (Balshine-Earn and Lotem, 1998). While it is yet unclear which individual signatures afford visual recognition among members of a social group, the colour patterns on the head including the black stripes are very plausible features for this accomplishment. Furthermore, Neolamprologus head and operculum markings may function in a way similar to "badges of status" as found in other taxa (Ferns and Hinsley, 2004; Rohwer, 1975; Setchell and Wickings, 2005; Tibbetts, 2006) and advertise the social status as helper, non-helper, and dominant breeder. Inter- and intraspecific discrimination through vision plays a crucial role in many cichlids (Carleton et al., 2005; Seehausen and van Alphen, 1998), but other sensory

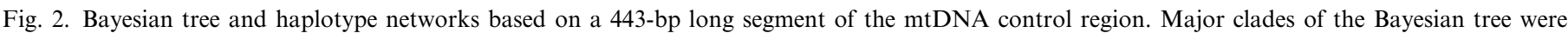

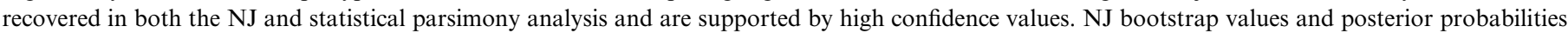

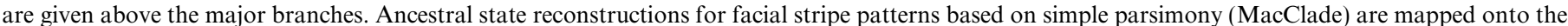

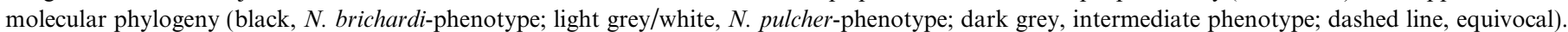

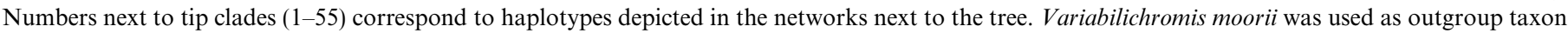

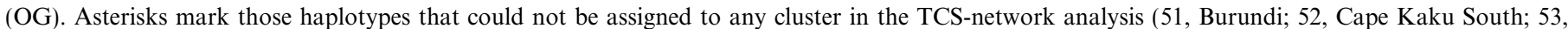

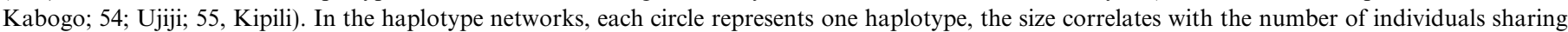

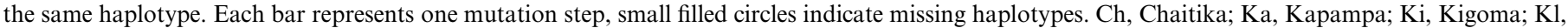

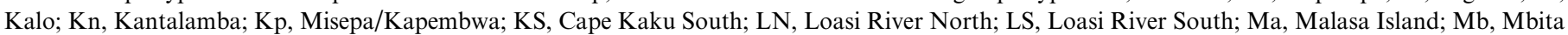
Island; Mp, Mpulungu; Mt, Mtondwe Island; To, Tongwa. 
modalities such as acoustic communication (Amorim et al., 2004; Lobel, 1998; Ripley et al., 2002) and olfaction (Cole and Stacey, 2006; Crapon de Caprona, 1980; Plenderleith et al., 2005) were also shown to mediate aspects of intraand interspecific signalling.

There is no evidence suggesting that the parallel evolution of the two stripe patterns results from ecological selection. Also, given that $N$. brichardi/N.pulcher are sexually monomorphic and possess the characteristic facial pattern already in an immature state, it does not seem to be important in mate choice, and there are no signs pointing to an influence of intersexual selection. The divergent bar patterns are not utilised during social disputes such as threat displays, where instead the ubiquitous dark blotch on the operculum becomes prominent. Therefore, intrasexual selection is also unlikely to be a causal agent for the observed stripe patterns. Purely random variation is not responsible either, because intrapopulation variation seems to be low, although stringent tests are missing (Konings, 1998, pers. observ.). The facial stripe patterns in these lamprologine taxa may thus be mainly shaped by natural selection for performance as signals of identity at the level of intrapopulation and intrafamily communication. This type of social selection could afford some freedom for diversification between populations, perhaps influenced by covarying arbitrary sensory biases (Endler and Houde, 1995; Maan et al., 2006) and under the constraint of maintaining the communicative function. As described above, distinct head stripe patterns are found in several other Neolamprologus species, and there may be a predisposition for variability of this trait within the group. Crosses between the two phenotypes may help to determine the genetic mechanisms underlying the different facial stripe patterns.

\subsection{Species assignment: $N$. brichardi and $N$. pulcher most likely represent one single species}

According to current taxonomic classification based on morphological characters and colour patterns, $N$. brichardi and $N$. pulcher represent two independent species (Poll, 1974) with non-overlapping distribution ranges along the shores of Lake Tanganyika (Konings, 1998). However, new measurements of 13 morphological characters of $N$. brichardi and $N$. pulcher specimens from two populations sampled at the northern and southern end of Lake Tanganyika, respectively, questioned the current classification (E. Skubic, S. Balshine, A. Grantner and M. Taborsky, unpublished data). The only quantitative differences found concerned head length and body depth, and the latter was only significantly different in males indicating that this trait might have been subject to sexual selection.

Our analysis of the most variable part of the mitochondrial control region shows that N. brichardi and N. pulcher populations are genetically extremely diverse. Among the 81 individuals sequenced, 55 haplotypes were found. In contrast to traditional taxonomic expectations, $N$. brichar$d i$ and $N$. pulcher were consistently resolved in mixed clades, and a tree consistent with reciprocal monophyly of the two phenotypes was rejected by a Kishino-Hasegawa test $(p<0.001)$. Moreover, except for one clade (Clade II), none of the major lineages comprised solely haplotypes from populations sampled in close geographic proximity to each other. Instead, haplotypes were spread over large distances along the shore and were sometimes distributed on opposite sides of the lake. Samples from Chaitika that resemble intermediate forms between the two phenotypes (Konings, 1998) were resolved in a clade that contains both $N$. pulcher and $N$. brichardi phenotypes (Fig. 2). Given the high sequence diversity between scattered clades of brichardi-type samples and the overall phylogeographic structure it is highly unlikely that the species boundaries are obscured as a consequence of incomplete lineage sorting. On the other hand, we cannot completely rule out the possibility of mitochondrial introgression due to hybridization between two previously independently evolving population entities. In the light of our results, we suggest to treat $N$. brichardi and $N$. pulcher as one species in the future. Because N. pulcher was described in 1952 (Trewavas and Poll, 1952) while N. brichardi was described only 22 years later (Poll, 1974), N. pulcher has precedence as species designation.

\subsection{Congruent phylogeographic patterns across rock- dwelling species}

The strong genetic differentiation and the lack of shared haplotypes among neighbouring populations (Fig. 2) suggest that dispersal is confined to short distances. This might be mainly due to the social system of $N$. brichardi and $N$. pulcher (compare Painter et al., 2000; Peterson, 1992), where helpers usually remain in the natal territory and assist in defending the nest and taking care of the brood (Taborsky, 1984; Taborsky and Limberger, 1981) in exchange for increased survival (Heg et al., 2004; Taborsky, 1984), potential opportunities for their own reproduction (mainly males; Dierkes et al., in press, 1999; Heg et al., 2006; Taborsky, 1985), and territory inheritance (mainly females; Balshine-Earn et al., 1998; Dierkes et al., 2005). Helpers delay dispersal usually until long after reaching maturity and pay with their helping behaviour to be allowed to stay in the dominant's territory (Balshine-Earn et al., 1998; Bergmüller et al., 2005a,b; Bergmüller and Taborsky, 2005; Taborsky, 1985). The older the helpers get, the higher the likelihood that the breeders have been replaced by unrelated individuals, a transition which does not seem to affect helping behaviour (Taborsky, 1984). After leaving their natal territory, helpers may join nonreproductive aggregations, as was observed in $N$. brichardi populations in the north of Lake Tanganyika (Taborsky, 1984; Taborsky and Limberger, 1981) or alternatively, disperse and start to defend an own territory or join another group, as observed in $N$. pulcher in the south of the lake (Bergmüller et al., 2005b; Stiver et al., 2004). It is important to note here that mitochondrial haplotypes as used in this 
study only cover the matrilineal history and might thus under- or overestimate the overall rate of migration and the extent of introgression between mtDNA-lineages. Indeed, Stiver et al. $(2007,2004)$ detected a tendency of large male-biased dispersal between subpopulations (i.e., aggregations of social groups separated from the neighbouring subpopulations by $10-100 \mathrm{~m}$ of unsuitable habitat), which goes hand in hand with a higher replacement rate of male breeders and consequently, a higher relatedness of helpers to the breeding female (Dierkes et al., 2005; Stiver et al., 2005, 2006).

The peculiar phylogenetic pattern where geographically distant populations clustered together while populations sampled in nearby locations were resolved in different clades has already been observed in other rock-dwelling cichlids in Lake Tanganyika (Baric et al., 2003; Rüber et al., 2001; Sturmbauer et al., 2005). In particular, the occurrence of closely related haplotypes on opposite sides of the lake was also found in several rock-dwelling cichlids of various life-styles such as the biparentally mouthbrooding Eretmodines (Rüber et al., 2001), the maternally mouthbrooding Tropheus spp. (Baric et al., 2003; Sturmbauer et al., 2005) and the substrate-spawning Variabilichromis moorii (Duftner et al., 2006). The congruence in phylogeographic patterns across highly divergent species (e.g. from the tribes Lamprologini and Tropheini) was attributed to shared environmental triggers such as geologically or climatologically induced lake level fluctuations (Sturmbauer et al., 2001, 2005). During periods of extremely low lake levels, cichlids confined to coastal regions may have crossed the lake along the major lake basin ridges (Baric et al., 2003; Rüber et al., 2001; Sturmbauer et al., 2005; Verheyen et al., 1996) or along the extending canyon of the Lufubu River, one of the few major tributaries to the lake (Duftner et al., 2006; Sturmbauer et al., 2005). By analyzing phylogeographic structures of currently widely distributed species adapted to different environmental conditions and by relating them to geological data on the history of the lake we will be able to further extend our knowledge on past colonization routes and speciation events in Tanganyikan cichlids. In addition to mitochondrial DNA, the application of nuclear markers will be necessary to comprehensively evaluate the extent of introgression among different populations and species.

\section{Acknowledgments}

We are grateful to the staff of the Department of Fisheries of the Ministry of Agriculture and Cooperatives at Mpulungu, Zambia, for their cooperation during fieldwork. L. Makasa, B. Kirchberger, and B. Egger helped in collecting samples during field trips in 2001 and 2002. We thank L. Rüber, H. Büscher, and S. Balshine-Earn for providing the majority of samples, and $\mathrm{A}$. Konings and $\mathrm{H}$. Büscher for providing photographs. H. Hofmann, S. Jorge, P. Unterwaditzer and an anonymous reviewer gave valuable comments on earlier versions of the manuscript. This study was supported by the Austrian Science Foundation (grant P15239) and the University of Graz. N.D. received a DOC-FFORTE-fellowship (Women in Research and Technology), and S.K. a DOC-fellowship, both provided by the Austrian Academy of Sciences. K.M.S. and S.K. were supported by Austrian Science Foundation Grant P17380. N.D. was further supported by an Erwin Schrödinger Fellowship from the Austrian Science Foundation, and the Bauer Center for Genomics Research at Harvard University. M.T. was supported by the Swiss National Science Foundation (SNSF grant 3100A0-105626).

\section{References}

Allender, C.J., Seehausen, O., Knight, M.E., Turner, G.F., Maclean, N., 2003. Divergent selection during speciation of Lake Malawi cichlid fishes inferred from parallel radiations in nuptial coloration. Proc. Natl. Acad. Sci. USA 100, 14074-14079.

Amorim, M.C.P., Knight, M.E., Stradoudakis, Y., Turner, G.F., 2004. Differences in sounds made by courting males of three closely related Lake Malawi cichlid species. J. Fish Biol. 65, 1358-1371.

Balshine-Earn, S., Lotem, A., 1998. Individual recognition in a cooperatively breeding cichlid: evidence from video playback experiments. Behaviour 135, 369-386.

Balshine-Earn, S., Neat, F.C., Reid, H., Taborsky, M., 1998. Paying to stay or paying to breed? Field evidence for direct benefits of helping behavior in a cooperatively breeding fish. Behav. Ecol. 9, 432-438.

Balshine, S., Leach, B., Neat, F., Reid, H., Taborsky, M., Werner, N., 2001. Correlates of group size in a cooperatively breeding cichlid fish (Neolamprologus pulcher). Behav. Ecol. Sociobiol. 50, 134-140.

Baric, S., Salzburger, W., Sturmbauer, C., 2003. Phylogeography and evolution of the Tanganyikan cichlid genus Tropheus based upon mitochondrial DNA sequences. J. Mol. Evol. 56, 54-68.

Bergmüller, R., Heg, D., Taborsky, M., 2005a. Extended safe havens and between group dispersal of helpers in a cooperatively breeding cichlid. Behaviour 142, 1643-1667.

Bergmüller, R., Heg, D., Taborsky, M., 2005b. Helpers in a cooperatively breeding cichlid stay and pay or disperse and breed, depending on ecological constraints. Proc. Roy. Soc. B 272, 325-331.

Bergmüller, R., Taborsky, M., 2005. Experimental manipulation of helping in a cooperative breeder: helpers 'pay to stay' by pre-emptive appeasement. Anim. Behav. 69, 19-28.

Boughman, J.W., Rundle, H.D., Schluter, D., 2005. Parallel evolution of sexual isolation in sticklebacks. Evolution 59, 361-373.

Brower, A.V.Z., 2006. Parallel race formation and the evolution of mimicry in Heliconius butterflies: a phylogenetic hypothesis from mitochondrial DNA sequences. Evolution 50, 195-221.

Carleton, K.L., Parry, J.W., Bowmaker, J.K., Hunt, D.M., Seehausen, O., 2005. Colour vision and speciation in Lake Victoria cichlids of the genus Pundamilia. Mol. Ecol. 14, 4341-4353.

Chiari, Y., Vences, M., Vieites, D.R., Rabemananjara, F., Bora, P., Ramilijaona Ravoahangimalala, O., Meyer, A., 2004. New evidence for parallel evolution of colour patterns in Malagasy poison frogs (Mantella). Mol. Ecol. 13, 3763-3774.

Clement, M., Posada, D., Crandall, K.A., 2000. TCS: a computer program to estimate gene genealogies. Mol. Ecol. 9, 1657-1659.

Cole, T.B., Stacey, N.E., 2006. Olfactory responses to steroids in an African mouth-brooding cichlid, Haplochromis burtoni (Günther). J. Fish Biol. 68, 661-680.

Colombe, J., Allgayer, R., 1985. Déscription de Variabilichromis, Neolamprologus et Paleolamprologus, genres nouveaux du lac Tanganyika, avec redescription des genres Lamprologus Schilthuis 1891 et de Lepidiolamprologus Pellegrin 1904. Rev. Fr. Cichlid 49, 9-28.

Crapon de Caprona, M.D., 1980. Olfactory communication in a cichlid fish, Haplochromis burtoni. Z. Tierpsychol., 52. 
Dierkes, P., Heg, D., Taborsky, M., Skubic, E., Achmann, R., 2005. Genetic relatedness in groups is sex-specific and declines with age of helpers in a cooperatively breeding cichlid. Ecol. Lett. 8, 968-975.

Dierkes, P., Taborsky, M., Achmann, R., in press. Multiple paternity in the cooperatively breeding fish Neolamprologus pulcher. Behav. Ecol. Sociobiol.

Dierkes, P., Taborsky, M., Kohler, U., 1999. Reproductive parasitism of broodcare helpers in a cooperatively breeding fish. Behav. Ecol. 10, 510-515.

Duftner, N., Sefc, K.M., Koblmüller, S., Nevado, B., Verheyen, E., Phiri, H., Sturmbauer, C., 2006. Distinct population structure in a phenotypically homogeneous rock-dwelling cichlid fish from Lake Tanganyika. Mol. Ecol. 15, 2381-2395.

Endler, J.A., Houde, A.E., 1995. Geographic variation in female preferences for male traits in Poecilia reticulata. Evolution 49, 456-468.

Ferns, P.N., Hinsley, S.A., 2004. Immaculate tits: head plumage pattern as an indicator of quality in birds. Anim. Behav. 67, 261-272.

Hasegawa, M., Kishino, H., 1989. Confidence limits on the maximumlikelihood estimate of the hominoid tree from mitochondrial-DNA sequences. Evolution 43, 627-677.

Hasegawa, M., Kishino, H., Yano, T., 1985. Dating the human-ape split by a molecular clock of mitochondrial DNA. J. Mol. Ecol. 22, 160174.

Heg, D., Bachar, Z., Brouwer, L., Taborsky, M., 2004. Predation risk is an ecological constraint for helper dispersal in a cooperatively breeding cichlid. Proc. Roy. Soc. B 271, 2367-2374.

Heg, D., Bergmüller, R., Bonfils, D., Otti, O., Bachar, Z., Burri, R., Heckel, G., Taborsky, M., 2006. Cichlids do not adjust reproductive skew to the availability of independent breeding options. Behav. Ecol. 17, 419-429.

Hert, E., 1985. Individual recognition of helpers by the breeders in the cichlid fish Lamprologus brichardi (Poll 1974). Z. Tierpsychol. 68, 313325.

Hoekstra, H.E., Hirschmann, R.J., Bundey, R.A., Insel, P.A., Crossland, J.P., 2006. A single amino acid mutation contributes to adaptive beach mouse color pattern. Science 313, 101-104.

Hoekstra, H.E., Price, T., 2004. Parallel evolution is in the genes. Science 303, 1779-1781.

Hoffman, E.A., Blouin, M.S., 2000. A review of colour and pattern polymorphisms in anurans. Biol. J. Linn. Soc. 70, 633-665.

Huelsenbeck, J.P., Ronquist, F., 2001. MrBayes: bayesian inference of phylogenetic trees. Biometrics 17, 754-755.

Jiggins, C.D., Mallarino, R., Willmott, K.R., Bermingham, E., 2006. The phylogenetic pattern of speciation and wing pattern change in neotropical Ithomia butterflies (Lepidptera: Nymphalidae). Evolution 60, 1454-1466.

Joron, M., Jiggins, C.D., Papanicolaou, A., McMillan, W.O., 2006. Heliconius wing patterns: an evo-devo model for understanding phenotypic diversity. Heredity 97, 157-167.

Kishino, H., Hasegawa, M., 1989. Evaluation of the maximum likelihood estimate of the evolutionary tree topologies from DNA sequence data, and the branching order in Hominoidea. J. Mol. Ecol. 29, 170-179.

Koblmüller, S., Salzburger, W., Sturmbauer, C., 2004. Evolutionary relationships in the sand-dwelling cichlid lineage of Lake Tanganyika suggest multiple colonization of rocky habitat and convergent origin of biparental mouthbrooding. J. Mol. Ecol. 58, 79-96.

Koblmüller, S., Sefc, K.M., Duftner, N., Warum, M., Sturmbauer, C., 2007. Genetic population structure as indirect measure of dispersal ability in a Lake Tanganyika cichlid. Genetica 130, 121-131.

Kocher, T.D., Thomas, W.K., Meyer, A., Edwards, S., Pääbo, S., Villablanca, F.X., Wilson, A.C., 1989. Dynamics of mitochondrial DNA evolution in animals: amplification and sequencing with conserved primers. Proc. Natl. Acad. Sci. USA 86, 6196-6200.

Konings, A., 1998. Tanganyika cichlids in their natural habitat. Cichlid Press, El Paso.

Lee, W.-J., Conroy, J., Howell, H.W., Kocher, T.D., 1995. Structure and evolution of teleost mitochondrial control regions. J. Mol. Ecol. 41, 54-66.
Lobel, P.S., 1998. Possible species specific courtship sounds by two sympatric cichlid fishes in Lake Malawi, Africa. Environ. Biol. Fish 52, 443-452.

Maan, M.E., Hofker, K.D., van Alphen, J.J.M., Seehausen, O., 2006. Sensory drive in cichlid speciation. Am. Nat. 167, 947-954.

Maddison, W.P., Maddison, D.R., 1992. MacClade: analysis of phylogeny and character evolution. 3.04. Sinauer, Sunderland, Massachusetts.

Meyer, A., 2006. Repeating patterns of mimicry. PLoS Biol. 4, 1675-1677.

Painter, J.N., Crozier, R.H., Poiani, A., Robertson, R.J., Clarke, M.F., 2000. Complex social organization reflects genetic structure and relatedness in the cooperatively breeding bell miner, Manorina melanophrys. Mol. Ecol. 9, 1339-1347.

Peterson, A.T., 1992. Philopatry and genetic differentiation in the Aphelocoma jays (Corvidae). Biol. J. Linn. Soc. 47, 249-260.

Plenderleith, M., van Oosterhout, C., Robinson, R.L., Turner, G.F., 2005. Female preference for conspecific males based on olfactory cues in Lake Malawi cichlid fish. Biol. Lett. 1, 411-414.

Poll, M., 1974. Contribution a la faune ichthyologique du lac Tanganyika, d'apres les racoltes de P. Brichard. Rev. Zool. Afr. 88, 99-100.

Poll, M., 1986. Classification des Cichlidae du lac Tanganika, tribus, genres et espéces. Acad. R. Belg. Mém. Cl. Sci. 45, 1-163.

Posada, D., Crandall, K.A., 1998. Modeltest: testing the model of DNA substitution. Bioinformatics 14, 817-818.

Prud'homme, B., Gompel, N., Rokas, A., Kassner, V.A., Williams, T.M., Yeh, S.-D., True, J.R., Carroll, S.B., 2006. Repeated morphological evolution through cis-regulatory changes in a pleiotropic gene. Nature $440,1050-1053$.

Rambaut, A., 1996. SE-AL: sequence Alignment Editor.

Ripley, J.L., Loebel, P.S., Yan, H.Y., 2002. Correlation of sound production with hearing sensitivity in the Lake Malawi cichlid Tramitichromis intermedius. Bioacoustics 12, 238-240.

Rohwer, S., 1975. The social significance of avian winter plumage variability. Evolution 29, 593-610.

Rüber, L., Meyer, A., Sturmbauer, C., Verheyen, E., 2001. Population structure in two sympatric species of the Lake Tanganyika cichlid tribe Eretmodini: evidence for introgression. Mol. Ecol. 10, 12071225.

Salzburger, W., Baric, S., Sturmbauer, C., 2002. Speciation via introgressive hybridization in East African cichlids? Mol. Ecol. 11, 619-625.

Sanders, K.L., Malhotra, A., Thorpe, R.S., 2006. Evidence for a Müllerian mimetic radiation in Asian pitvipers. Proc. Roy. Soc. B 273, 1135-1141.

Seehausen, O., Mayhew, P.J., van Alphen, J.J.M., 1999. Evolution of colour patterns in East African cichlids. J. Evol. Biol. 12, 514-534.

Seehausen, O., van Alphen, J.J.M., 1998. The effect of male coloration on female mate choice in closely related Lake Victoria cichlids (Haplochromis nyererei complex). Behav. Ecol. Sociobiol. 42, 1-8.

Sefc, K.M., Baric, S., Salzburger, W., Sturmbauer, C., 2007. Speciesspecific population structure in rock-specialized sympatric cichlid species in Lake Tanganyika, East Africa. J. Mol. Evol. 64, 33-49.

Setchell, J.M., Wickings, J.E., 2005. Dominance, status signals and coloration in male mandrills (Mandrillus sphinx). Ethology 111, 25-50.

Stiver, K.A., Desjardins, J.K., Fitzpatrick, J.L., Neff, B., Quinn, J.S., Balshine, S., 2007. Evidence for size and sex-specific dispersal in a cooperatively breeding cichlid fish. Mol. Ecol. 16, 2974-2984.

Stiver, K.A., Dierkes, P., Taborsky, M., Balshine, S., 2004. Dispersal patterns and status change in a co-operatively breeding cichlid Neolamprologus pulcher: evidence from microsatellite analyses and behavioural observations. J. Fish Biol. 65, 91-105.

Stiver, K.A., Dierkes, P., Taborsky, M., Gibbs, H.L., Balshine, S., 2005. Relatedness and helping in fish: examining the theoretical predictions. Proc. Roy. Soc. B 272, 1593-1599.

Stiver, K.A., Fitzpatrick, J., Desjardins, J.K., Balshine, S., 2006. Sex differences in rates of territory joining and inheritance in a cooperatively breeding cichlid fish. Anim. Behav. 71, 449-456.

Sturmbauer, C., Baric, S., Salzburger, W., Rüber, L., Verheyen, E., 2001. Lake level fluctuations synchronize genetic divergence of cichlid fishes in African lakes. Mol. Biol. Evol. 18, 144-154. 
Sturmbauer, C., Koblmüller, S., Sefc, K.M., Duftner, N., 2005. Phylogeographic history of the genus Tropheus, a lineage of rock-dwelling cichlid fishes endemic to Lake Tanganyika. Hydrobiologia 542, 335366.

Sturmbauer, C., Verheyen, E., Meyer, A., 1994. Mitochondrial phylogeny of the Lamprologini, the major substrate spawning lineage of cichlid fishes from Lake Tanganyika in Eastern Africa. Mol. Biol. Evol. 11, 691-703.

Swofford, D., 2000. PAUP* 4.0b10: phylogenetic analysis using parsimony. Sinauer, Sunderland, Massachusetts.

Taborsky, M., 1984. Broodcare helpers in the cichlid fish Lamprologus brichardi: their costs and benefits. Anim. Behav. 32, 1236-1252.

Taborsky, M., 1985. Breeder-helper conflict in a cichlid fish with brood care helpers: an experimental analysis. Behaviour 95, 45-75.

Taborsky, M., 1994. Sneakers, satellites and helpers: parasitic and cooperative behaviour in fish reproduction. Adv. Study Behav. 23, $1-100$.

Taborsky, M., Limberger, D., 1981. Helpers in fish. Behav. Ecol. Sociobiol. 8, 143-145.
Taylor, M.I., Rüber, L., Verheyen, E., 2001. Microsatellites reveal high levels of population substructuring in the species-poor Eretmodine cichlid lineage from Lake Tanganyika. Proc. Roy. Soc. B 268, 803-808.

Templeton, A.R., Crandall, K.A., Sing, C.F., 1992. A cladistic analysis of phenotypic associations with haplotypes inferred from restriction endonuclease mapping and DNA sequence data III. Cladogram estimation. Genetics 132, 619-633.

Thorpe, R.S., Stenson, A.G., 2003. Phylogeny, paraphyly and ecological adaptation of the colour and pattern in the Anolis roquet complex on Martinique. Mol. Ecol. 12, 117-132.

Tibbetts, E.A., 2006. Badges of status in worker and gyne Polistes dominulus wasps. Ann. Zool. Fennici 43, 575-582.

Trewavas, E., Poll, M., 1952. Three new species and two new subspecies of the genus Lamprologus, cichlid fishes of Lake Tanganyika. Bull. Inst. Sc. nat. Belgique 28, 1-16.

Verheyen, E., Rüber, L., Snoeks, J., Meyer, A., 1996. Mitochondrial phylogeography of rock-dwelling cichlid fishes reveals evolutionary influence of historical lake level fluctuations of Lake Tanganyika. Proc. Roy. Soc. B 351, 797-805. 